\title{
CAPÍTULOS ENTRE MURCIA Y ORIHUELA. RELACIONES DE FRONTERA (1427)
}

\author{
Clara ALARCÓN RUIZ \\ Julio NAVARRO MOLTÓ \\ Rafaela VIDAL FERNÁNDEZ
}

Este estudio persigue mostrar un ejemplo más de la compleja y azarosa vida fronteriza, situación que sufrieron y/o "aprovecharon» como nadie los habitantes del adelantamiento murciano. Estos tuvieron que adaptarse a la problemática derivada de la existencia de las tres fronteras por las que se encontraban rodeados casi por completo: la aragonesa, la granadina y la mediterránea.

Pero antes de adentrarnos en profundidad en el desarrollo de esta cuestión, procedamos en primer lugar a la contextualización del documento en el que basamos esta comunicación.

En 1427 había transcurrido algo más de una centuria desde que Murcia acordase nueva frontera con Aragón; fue concretamente a partir de la sentencia de Torrellas, y la reforma en Elche, donde Guardamar, Orihuela, Elche y Novelda pasan a manos del monarca aragonés. El reino de Murcia había perdido su zona norte y Castilla una parte importante de su litoral.

Sin embargo, los limes que se establecen son bastante imprecisos, por lo que en adelante fueron numerosas las ocasiones en que representantes de ambos reinos tuvieron que reunirse para definir con mayor claridad la línea fronteriza, ya que su imprecisión era motivo constante de conflictos'.

Nos parece importante, al tratar el tema del reparto del territorio murciano, dirigir la mirada más allá del exclusivo punto de vista político. Murcia y Orihuela quedaban ahora

1 MARTÍNEZ CARRILLO, Mª . LI., Revolución urbana y autoridad monárquica en Murcia durante la Baja Edad Media (1395-1420). Murcia, 1980, p. 203. 
englobadas en dos unidades políticas diferentes al convertirse en cabeza del sistema fronterizo castellano y aragonés respectivamente. Las dos ciudades hermanas eran ahora "centros polarizadores de dos áreas enfrentadas e incompatibles»².

Pero además, se había establecido desde el punto de vista geográfico, una frontera artificial. Los pasillos orográficos que durante largo tiempo habían unido y facilitado las relaciones entre estas localidades vecinas, quedaban ahora partido por unos acuerdos totalmente arbitrarios ${ }^{3}$. Se llega a hablar de frontera "antigeográfica». En definitiva, «la política se impuso a lo que la naturaleza y el quehacer de los hombres habían unido" ${ }^{4}$.

Ciertos cronistas oriolanos también se hacen eco de esta circunstancia, es el caso de Gisbert y Ballesteros que, en su obra «Historia de Orihuela», lamenta las contiendas y reyertas que frecuentemente se dieron entre murcianos y oriolanos, "selladas no pocas veces, con la sangre de quienes siempre han debido considerarse como hermanos, como hijos de una misma vega y ligadas aunque no quieran por los mismos intereses" 5 .

El documento, además de hacer alusión a la frontera aragonesa, también se refiere a la que el reino murciano mantiene con Granada, frontera que permanece sin variaciones importantes durante más de dos centurias, desde 1266 a $1486^{6}$.

Se trata de una extensa «tierra de nadie» donde la escasez de población es la característica dominante. Circunstancia esta que queda reflejada en el siguiente texto que recoge Torres Fontes: "desde Xiquena, nueve leguas de tierra despoblada, e toda a peligro de moros"' 7 . Parcas palabras pero extraordinariamente clarificadoras, como lo son de la misma manera las reflexiones que sobre esta cuestión realiza Rodríguez Llopis y que nos parece interesante destacar aquí; dice el autor que "el despoblamiento se constituye en la consecuencia lógica de una sociedad que vive para la guerra; la población se contrae para mejor defenderse, y en ello encuentra su pervivencia.... ${ }^{8}$.

Grave problema este vacío humano del que hablamos para la defensa del territorio, por lo que hubo de adoptar una serie de medidas para subsanarlo. Una de ellas fue la concesión del privilegio del derecho de asilo a «homicianos». Así la frontera se convierte en «refugio de malhechores, violadores y homicidas»" ${ }^{9}$, in olvidarnos de los nobles desterrados de la corte.

2 VILAR, J.B., Historia de la ciudad de Orihuela. T. III. Los siglos XIV y XV en Orihuela. Murcia, 1977, p. 307.

3 MARTÍNEZ CARRILLO, M․ LI., Op. cit, p. 195.

4 Historia de España. Dirigida por J.Ma . Jover Zamora. T. XIII. I. Madrid, 1990, p. 484.

5 GISBERT Y BALLESTEROS, D., Historia de Orihuela. Orihuela, 1903.

6 TORRES FONTES, J., «La actividad bélica granadina en la frontera murciana (ss. XIII-XV)». Príncipe de Viana, 3 (1986). Homenaje a J.M ${ }^{a}$. Lacarra, pp. 721-739, p. 721.

7 TORRES FONTES, J., «Enrique IV y la frontera de Granada. (Las treguas de 1458, 1460, y 1461)". Homenaje al profesor Carriazo. Sevilla, 1973, pp. 345-380, p. 346.

8 RODRÍGUEZ LLOPIS, M., Señorios y feudalismo en el reino de Murcia. Univ. de Murcia, 1986, p. 51.

9 JIMÉNEZ ALCÁZAR, J.F., Huércal y Overa: de enclaves nazaries a villas cristianas (12441571). Huercal-Overa, 1996, p. 29. 
Por otra parte, aunque sin abandonar la frontera entre el reino nasrí de Granada y el castellano en su sector murciano, no debemos pensar en la existencia de una clara y precisa línea divisoria entre ambos. Los verdaderos límites quedaban marcados por un rosario de torres y atalayas, de puntos fuertes que se extienden a lo largo de esa tierra de nadie $^{10}$.

Hasta aquí, algunas puntualizaciones de carácter general sobre los dos sectores fronterizos; completaremos estos datos con una visión política y diplomática global de los tres reinos - granadino, castellano y aragonés- en el momento en que se redacta el documento objeto de este estudio, esto es, abril de 1427.

A Granada la hallamos sumida en un proceso de inestabilidad del que ya no podrá salir. Muhammad VIII y su tío Muhammad IX, apoyados por Alamines y Abencerrajes respectivamente, las dos facciones más poderosas en el reino nazari durante el siglo $X V^{11}$, llevan practicando el juego del derrocamiento desde hace varios años. A comienzos de 1427 llega el turno de gobierno a Muhammad VIII, que tuvo que abandonarlo en beneficio de su tío, conocido como el Izquierdo, antes de finalizar el año. Nos encontramos inmersos en una guerra civil que conducirá al emirato a su propia destrucción.

En Castilla también se lucha por el poder; esta vez la pugna se desarrolla entre don Álvaro de Luna, los infantes de Aragón y las ligas nobiliarias. Distintas facciones pero un sólo objetivo: riqueza y, sobre todo, poder. Frente a estos Juan II, indolente soberano que deja las riendas de su política en manos de su valido.

Por su parte, Aragón cuenta con la figura, que no con la presencia, de Alfonso $V$ el Magnánimo, más interesado en ampliar las fronteras de su Corona por mar que por tierra $^{12}$. Al mismo tiempo, se observa el crecimiento de la alta nobleza aragonesa ante la ausencia de toda autoridad regia.

Centrándonos en el adelantamiento murciano, la figura indiscutible es el que denomina Cascales «belicosisimo caballero" " ${ }^{13}$; se trata del segundo Alonso Yáñez Fajardo. Como adelantado mayor, cargo al que accede en 1424, le incumbía «el mantenimiento de la paz pública en su circunscripción, preservando el territorio y sus pobladores de todo mal o daño, como asomadas o revueltas ${ }^{14}$. $Y$ a éste fin dedicó su vida, pero con tal empeño y exhibiendo tan espléndidas cualidades guerreras y políticas, que le hicieron merecedor, en 1430 , del cargo de capitán mayor «de la frontera de la guerra de los moros" 15 .

Este es el panorama interno que presentan los tres reinos, pero la cuestión que nos interesa destacar aquí es la política que cada uno de ellos despliega con respecto a los demás. Hablemos pues, de política exterior, de diplomacia.

10 JIMÉNEZ ALCÁZAR, J.F., Lorca: ciudad y término. Lorca, 1994, p. 150.

11 TAPIA GARRIDO, J.A., Historia de la Vera Antigua. Almería, 1987, p. 235.

12 VILAR, J.B., Op. cit., p. 307.

13 TAPIA GARRIDO, J.A., Op. cit, p. 111.

14 GARCÍA DE VALDEAVELLANO, L., Curso de las instituciones españolas. Madrid, 1977, p. 510.

15 TORRES FONTES, J., "Los Fajardo en los siglos XIV y XV». M.M.M., IV, 1978, Univ. de Murcia, pp. 107-175, p. 137. 
Como punto de partida, resaltar la privilegiada situación de Castilla en el panorama peninsular y su peso cada vez mayor en el acontecer político de los reinos hispánicos. A pesar de su manifiesta superioridad militar, la inestabilidad interna que atravesaba, ya hemos comentado, era motivo de peso para no desplegar una firme política defensiva contra el enemigo musulmán. Por otra parte, de éste tenía asegurado el cobro del tributo anual o parias.

Por lo que respecta a Aragón ya hablamos de las preferencias extrapeninsulares mostradas por su monarca, lo que le llevará a buscar relaciones pacíficas en el interior de la península, sobre todo con Granada; manifestación de ello son, por ejemplo, el envío de emisarios o la firma de acuerdos comerciales ${ }^{16}$.

El mantenimiento de la paz y el establecimiento de buenas relaciones parece ser el objetivo de los tres monarcas, lo que se plasmó en la firma de una serie de acuerdos entre los mismos. Como ya hemos apuntado anteriormente, en enero de 1427 el trono de Granada cambia de manos lo que implica que la tregua firmada en 1426 entre el monarca granadino depuesto y Castilla deja de tener vigor; con toda premura los soberanos de ambos reinos, en un intento de evitar el estallido de incidentes, se disponen a negociar una nueva tregua, la cual va a tener comienzo oficial el 16 de febrero de $1427^{17}$.

Habría que destacar cómo el juego político de treguas entre Aragón y Granada, Granada y Castilla o entre Aragón y Castilla venían a crear en el Sureste peninsular una situación interesante. Por ejemplo, en momentos en los que Granada tiene rota la tregua con Castilla, pero no con Aragón, cómo ocurrió en 1407, los aragoneses - concretamente los oriolanos - no pueden atender, al menos oficialmente, la llamada de ayuda que les llega desde el adelantamiento murciano, aunque como apunta Bellot: «muchos caballeros vendrán a la deshilada» ${ }^{18}$.

Pero acercándonos de nuevo a los territorios fronterizos, aquí se debían hacer valer las treguas acordadas entre los monarcas. Cuestión ésta sin duda, harto difícil; y es que como apunta Carriazo, en la frontera ni la guerra era guerra, ni la paz era paz, ni siquiera las treguas eran treguas, en el pleno sentido del concepto ${ }^{19}$.

El estado normal de la frontera en tiempos de paz venía marcado por las constantes algaras, cabalgadas e incursiones más o menos profundas que llevaban a cabo fronteros de uno u otro lado. Situación ésta que algunos autores han venido a denominar de "semibeligerancia, guerra atenuada»" 0 "guerra chica»"

16 TORRES FONTES, J., «Relaciones castellano-granadinas (1427-1430)». IV Coloquio de His" toria Medieval Andaluza. I.E.A., 1988, p. 86.

17 TORRES FONTES, J., “Las relaciones castellano-granadinas desde 1416 a 1432. !. Las treguas de 1417 a 1426». Cuadernos de Estudios Medievales, VI-VII, pp. 297-312, p. 311.

18 CARRIAZO ARROQUIA, J.M., «Un alcalde entre los cristianos y los moros en la frontera de Granada". En la frontera de Granada. Homenaje al profesor Carriazo. Sevilla, 1971, pp. 87-142, p. 138.

19 Ibídem, p. 139.

20 lbídem.

21 TORRES FONTES, J., «La actividad bélica...», p. 732. 
Innumerables situaciones conflictivas que en ningún caso ponían en peligro la vigencia de la treguas. En este contexto político se hallaban las Coronas castellana, aragonesa y granadina a finales de la década de 1420-30. Precisamente en 1427, y como concreción de la tregua firmada en febrero de este año, se acuerdan entre Murcia, Orihuela y el sector fronterizo oriental de Granada - Vera, Huércal y los Vélez- unos capítulos en los que el adelantado murciano como máximo representante de la Corona castellana en su demarcación, intenta... poner remedio a los grandes males e daños e pérdidas, ofensas e injusticias e agravios... ${ }^{22}$ que acontecían como consecuencia de las frecuentes correrías que almogávares de los tres sectores citados llevaban a cabo. Es obligación de Alonso Yáñez Fajardo II «apuntalar» en el ámbito fronterizo suroriental las buenas relaciones que a nivel general se desean mantener.

Por otra parte y, como claramente se expresa en nuestro documento, los almogávares granadinos no limitan sus acciones a territorio murciano sino que penetran en Aragón, concretamente en la gobernación de Orihuela; y es que la distancia entre esta villa y los puntos más avanzados del reino de Granada no supera los 120 kms. ${ }^{23}$; a esta circunstancia se añade una orografía favorable -recordemos que la depresión prelitoral une Andalucía con Levante-, además de la existencia de numerosas aljamas en territorio cristiano que prestaban información y ayuda oportuna a los que venían de Granada.

Era habitual la represalia por parte de los oriolanos que se aventuraban hasta tierras de Granada con la finalidad del robo y cautiverio. La contestación granadina no se hacía esperar «pero en vez de verificarla en la gobernación de Orihuela lo hacían en el reino de Murcia, como territorio más cercano a su frontera» ${ }^{24}$.

Es precisamente este constante trasiego de almogávares que recorren en todas direcciones el territorio murciano, ocasionándose por ello muchas muertes e otros males ${ }^{25}$, lo que denuncia e intenta subsanar Alonso Yáñez Fajardo ll a través de estos capítulos. Sus disposiciones giran en torno a uno de los males endémicos que soportan los habitantes de la frontera: el cautiverio. El temor a ser sorprendidos por el enemigo, hizo que el ambiente normal que se respiraba en los lugares próximos a la frontera estuviera impregnado de una gran tensión e inquietud. $Y$ es que la frecuencia de los cautiverios aumentaba a la par que avanzaba el siglo; circunstancia que se aprecia con claridad en las condiciones impuestas en la firma de las treguas entre castellanos y granadinos, en las que cada vez es mayor el número de cautivos cristianos que se exigía fueran puestos en libertad ${ }^{26}$. La captura de enemigos se había convertido en un negocio que reportaba «pingües" beneficios por lo elevado de los rescates;

22 Ver Apéndice Documental.

23 MARTÍNEZ CARRILLO, Ma LL., Op. cit, p. 208.

24 TORRES FONTES, J., “Notas sobre los fieles del rastro y alfaqueques murcianos». M.E.A.H., $X(1969)$, pp. 89-105, p. 99.

25 Ver apéndice documental.

26 TORRES FONTES, J., «La frontera de Granada en el siglo XV y sus repercusiones en Murcia y Orihuela: Ios cautivos". Homenaje a J.M?. Lacarra. Vol. IV, Zaragoza, 1977, pp. 191-211, p. 192. 
no es de extrañar, por tanto, que fueran muchos los que convirtieran esta arriesgada actividad en su forma de vida.

El número de cristianos que sufrieron cautiverio, fue bastante superior al de musulmanes. Varias son las causas. La primera de ellas y la más importante es de orden económico. La mayor parte de los moros cautivos eran reducidos a esclavitud o canjeados por cristianos, eran muy pocos los que volvían a su lugar de origen tras haber recibido su captor un rescate en metálico. Con los cristianos ocurría lo contrario; las familias de los cautivos, con grandes dificultades en muchas ocasiones, lograban reunir las cantidades exigidas. Obtienen los musulmanes, de esta forma mayores beneficios que sus compañeros de oficio del otro lado de la frontera ${ }^{27}$.

Una segunda causa la encontramos en la desigualdad del dispositivo defensivo desplegado entre castellanos y granadinos. El sector oriental del reino nazarí presenta a lo largo de su frontera "un poblamiento concentrado muy denso, con muchos enclaves de pequeña y mediana importancia ${ }^{28}$, por lo que las incursiones por sorpresa resultan más difíciles de realizar que en los extensos despoblados castellanos.

Asaltos, correrías y violencias de todo tipo son el resultado del largo período en el que se mantuvo el límite entre el musulmán y el cristiano en el sureste peninsular. Pero durante este espacio de tiempo también se fueron generando toda una serie de instituciones tendentes a acabar o a mitigar en lo posible estas acciones. A una de ellas hace alusión nuestro documento, se habla en el de seguir el rastro ${ }^{29}$, los encargados de esto eran los llamados fieles del rastro, oficiales concejiles cuya tarea consistía en perseguir a los malhechores que entraban en su territorio. Su labor concluía cuando los presuntos autores del delito habían sido capturados o podía entregarse el rastro a los encargados de ello en la jurisdicción vecina ${ }^{30}$.

Conocido el paradero de los cautivos entraba en escena el alfaqueque. El oficio de la alfaquequería resulta ser la más clara evidencia de la frontera como generadora de instituciones; prueba de ello es que este personaje ya actuaba mucho antes de que estuviese instituido el oficio como tal. Así cuando en Las Partidas aparece el cargo de alfaqueque la intención de Alfonso $X$ «no es tan solo el resultado de una inquietud legislativa sino un atemperarse con la realidad fronteriza castellana» ${ }^{31}$.

Estos alfaqueques y «exeas» estaban encargados de llevar a cabo el canje o redención de cautivos, además de la recuperación de ganados u otras cosas robadas. Solían portar una carta concejil, una especie de acreditación o salvoconducto - normalmente aceptado por las diversas partes en liza- que les permitía la libre circulación y el paso a través de la frontera.

27 TORRES FONTES, J., «La frontera, sus hombres y sus instituciones». Murgetana, 57 (1987), pp. 71-116, p. 100.

28 JiMÉNEZ ALCÁZAR, J.F., Huércal y Overa: de enclaves nazaríes..., p. 13.

29 Ver apéndice documental.

30 TORRES FONTES, J., «Notas sobre los fieles...", p. 91.

31 TORRES FONTES, J., "Los alfaqueques castellanos en la frontera de Granada". Homenaje a Agustín Millares Carló. Las Palmas de Gran Canaria, 1975, pp. 99-116, p. 99. 
Pero quien realmente pone en movimiento toda esta maquinaria fronteriza es el adelantado. Alonso Yáñez Fajardo II se erige en arbitro de las situaciones conflictivas que acontecen en el sector fronterizo suroriental; a él compete establecer las disposiciones de los capítulos, disponiendo la persecución de los malhechores, demandando a los culpables la devolución de lo sustraído o bien una compensación en metálico, estableciendo el plazo en el tienen que llevarse a efecto las citadas devoluciones y compensaciones, etc.

Las relaciones fronterizas que tradicionalmente han suscitado mayor interés por parte de los investigadores son las que tienen como protagonistas a dos culturas, dos religiones diferentes; es por ello que los estudios en este campo se han centrado en la frontera entre Castilla y Granada. Sin embargo, la zona de contacto entre Aragón y Castilla en el adelantamiento murciano es un foco muy interesante para mostrar como a lo largo de la historia las divisiones territoriales artificiales, resultado de decisiones políticas, han afectado a la dinámica de una zona, tanto que incluso actualmente los problemas, aunque de otra índole siguen manteniéndose.

Murcia sigue sintiendo la cercanía oriolana como algo propio y Orihuela siente Alicante mucho más lejana tanto en la distancia física como en el arraigo histórico. 


\section{APÉNDICE DOCUMENTAL}

\section{7, abril, 15. (Orihuela)}

Carta de Alfonso Yáñez Fajardo al baile general del reino de Valencia y éste a los oficiales del concejo de Orihuela para la aprobación de unos capítulos. Inserta: 1427abril-17. Carta confirmando la aceptación de dichos capítulos. (A.M.O. Libro $\mathrm{n}^{\circ} 20$, fols. 90-93).

Don Pero Maça de Liçana conseller e mayordomi del molt alt senyor rey e gobernador de la gobernaçio de la vila d'Oriola en Antich Albarades justiçi de la dita vila en lo criminal en Antoni de Galbe e en Jaume Rocamora e en Bernat Despuig jurats de la dita vila vist sus capitols tramesos e fermats per part del adelantat e regidors e qonsell de la ciutat de Murçia los quals capitols son estants portats e presentats el molt honorable miser Johan Mercader baile general del regne de Valencia e per lo dit honorable baile enviats als dit gobernador e justiçi e jurats de la dita vila per Johan Peres de Bonmati scriba e notari del dit adelantat e qonsell de la dita ciutat dimarts qui es comptante quinze dies del mes de abril del any de la Nativitate de nostre senyor mil e quatrocens e vint e set por los quales capitols se mostren fermats de la ma e nom per part dit adelantat e de Lope Alfonso e de Pero Martinez de Ahuera regidors del dit qonsell de la dita ciutat de Murçia per tal nos dit gobernador lo ant aceptant los dits capitols fermats aquells de nostre propi nom e ma segons en la fi de aquells es contengut. E nosalters aixi mateix justiçi e jurats e qonsell de la dita vila aceptant los dits capitols donan poder an Jaume de Rius bacheller en leys e an Barthomeu Mosen de Castanyesa misatgers nomenats en los dits capitols que en nom nostre e de la dita universitat fermen los dits capitols e sots scriuen de sos propis noms e mans segons en la fi d'aquells es contengut los quals capitols son de la tenor seguent.

En el nombre de Dios.

Alfonso Yañez Fajardo adelantado mayor del regno de Murçia e Pero Martines de Ahuera e Lope Alfonso de Lorca regidores de la muy noble çibdat de Murçia, en nombre del conçejo,regidores, caballeros,escuderos, ofiçiales e omes buenos de la dicha çibdat, de la una parte en nombre de todo el dicho regno,realengo e señorios. E e de la otra parte Jayme de Rius, bachiller en leyes, e Bartolome Monsy de Castañiesa, habitadores e mensajeros del gobernador e justiçia e jurados de la villa de Orihuela, en nombre de los dichos gobernador,justiçia e jurados e conçejo e universidat de la dicha villa e de su gobernaçion,realengo e señorios. Por oviar e poner remedio a los grandes males e daños e perdidas, ofensas e injustiçias e agravios que son acaesçidos e suelen e se esperan acaesçer en los dichos regno e gobernaçion e en sus terminos, por causa e ocasion de las entradas que los moros del regno e señorio de Granada fasen por los terminos deste regno de Castilla deste dicho adelantamiento a los terminos de la dicha gobernaçion.E otrosy por las entradas que los vezinos de la dicha gobernaçion e otros fasen a la dicha tierra e señorio de Granada por termino de Castilla deste dicho adelantamiento fasiendose por alli guerra los unos a los otros, sobre lo 
qual son acaesçidas muchas muertes e otros males e se han sostenido muchos trabajos e muchas costas e despensas. Por esta rason ordenaron los capitulos siguientes.

Primeramente, que firmados estos dichos capitulos por los señores reyes de Castilla e de Aragon e por el rey de Granada, quel dicho adelantado aperçiba luego por sus cartas a los cabdillos e alcaydes e aljamas de Vera,e Veles e de Huerca e sus conquistas e de los otros lugares del dicho regno de Granada que son en la frontera deste dicho adelantamiento, que no entren por los dichos terminos del dicho adelantamiento a cativar omes ni faser otros males ni muertes a los dichos terminos de Orihuela e su gobernaçion, ni por alli a otros lugares del regno de Aragon.E otrosy que los de la dicha villa de Orihuela e de su gobernaçion, que no entraran por los dichos terminos de Murçia e de su adelantamiento a cativar moros ni a faser otros males ni muertes a las dichas conquistas de Vera e de Veles e Huerca, ni por alli a otras partes del dicho regno de Granada de aqui adelante, çerteficandoles que qualquier o qualesquier personas christianos o moros de amas las partes que fueren tomados en pasando,entrando o saliendo o estando seran luego muertos por justiçia e tornada la presa a la parte dabnificada.E si no fueren tomados, sera seguido el rastro, e sera demandado el robo e toma por el dicho adelantado a qualquier de las dos partes de Orihuela e su gobernaçion e de los dichos lugares e conquistas de Granada, e fara prendas e pagara a los dabnificados.E otrosy, quel dicho gobernador sea tenido de faser semejante aperçebimiento a todos los lugares de su gobernaçion e a los otros lugares comarcantes a ella.

Item que luego quel dicho adelantado o sus ofiçiales fueren çerteficados de algun salto o muertes o cativerios o robos que sean fechos por los dichos moros del dicho regno de Granada o por otras personas, en el termino de la dicha villa de Orihuela o en su gobernaçion, o por alli a otros lugares del dicho regno de Aragon, e fuere puesto el rastro de los malhechores en este termino de Murçia e en su adelantamiento, quel dicho adelantado o sus ofiçiales fagan tomar e seguir el rastro. E que si no fueren tomados los malhechores, demandara el dicho adelantado a los moros de la conquista donde entrare el rastro, o donde se sopiere que fue levado el robo, que lo paguen o su estimaçion sabida con gran deligençia la verdat del dicho daño, aunque por rastro no se falle. E si oviere muertes, que se pague por cada muerte quarenta doblas para la parte de los dabnificados, e las personas vivas que sean tornadas en toda manera, aunque sean trasportadas en otros regnos e señorios, en tal que se falle por verdat que por tierra sean levados o tomados pasando por el dicho adelantamiento por tierra en todo o en parte.E si los moros no lo cumplieren asi dentro en veinte dias del dia que fueren requeridos, quel dicho adelantado fara prendas bastantes por ello en los moros e las dara e entregara a los dichos gobernador e villa de Orihuela dentro en dos meses. E si dentro en el dicho plaso no lo fisiere, que los dichos gobernador e villa de Orihuela puedan faser prendas por ello en personas e bienes de la dicha çibdat de Murçia e de su adelantamiento fasta ser satisfechos de los dichos daños. E que desta guisa se entienda quel dicho adelantado ha de enmendar e satisfaçer a los moros de las dichas conquistas de las muertes e cativerios que resçibieren e les fueren fechos 
por parte de la dicha villa de Orihuela e su gobernaçion por el dicho adelantamiento.E que estas cosas suso dichas se fagan e cumplan a buena entençion e sin engaño de ninguna de las partes. E que el dicho adelantado aya cargo de faser firmar estos dichos capitulos al señor rey de Castilla e al rey de Granada,e el dicho gobernador al señor rey de Aragon, e que dure del dia que fueren confirmados en tres años complidos $e$ dende adelante en tanto tiempo quanto a todas las dichas partes plasera.

1427-abril-17. En hoy XVII dies d'abril en l'any de la Nativitate de nostre senyor mil e quatrecents e XXVII complits (?) en Johan Peres de Bonmati scriua public e notari del adelantat de la çiutat de Murçia e presenta als justiçi e jurats de la dita vila d'Oriola e en presençi del honorable miser Johan Mercader baile general de regne de Valençia dita carta del dit adelantat qui es de la tenor seguent.

A los mucho honorables el justiçia e jurados e consegeros de la vila de Orihuela.

Mucho honorables el justiçia e jurados e consegeros de la vila de Orihuela. Alfonso Yañez Fajardo, adelantado mayor del regno de Murçia, vos envio mucho a saludar como aquellos por quien de buena voluntat faga las cosas que a honra vuestra cumpla.Reçebi los capitulos que, de parte del senyor baylle e gobernador e vuestra, me fueron enviados con Johan Peres de Bonmati, mi scriuano, firmados de los nombres de don Pero Maza e de Jaime de Rius, bachiller, e Bartolome Mosin de Castanyesa, segun por ellos parecia et oi cosas quel dicho mi scriuano, de parte de los dichos bayle e gobernador e vuestra, me dixo. Las quales, por mi entendidas, le respondi segun que el vos dira plega a vos de lo oir e cierto de lo que acerca dello de parte mia el vos dixere e explicare. E Dios vos haya en su santa guarda.Scripta disisiete dias de abril.Alfonso Yañez. 